\title{
Correction to: Development and evaluation of an Urdu treebank (CLE-UTB) and a statistical parser
}

\section{Toqeer Ehsan ${ }^{1}$ (i) $\cdot$ Sarmad Hussain ${ }^{2}$}

\section{Correction to: Lang Resources \& Evaluation https://doi.org/10.1007/s10579-020-09492-7}

In the original publication of the article the column headers of the Tables 17 and 18 were incorrectly published. The corrected version of Tables 17 and 18 are provided with this Correction.

The original article has been corrected.

The original article can be found online at https://doi.org/10.1007/s10579-020-09492-7.

Toqeer Ehsan

toqeer.ehsan@gmail.com

Sarmad Hussain

sarmad.hussain@kics.edu.pk

1 Department of Computer Science and Engineering, University of Engineering and Technology,

Lahore, Pakistan

2 Center for Language Engineering (CLE), KICS/CS\&E, University of Engineering and Technology, Lahore, Pakistan 
Table 17 No. of sentences in train and test sets. Test set has been divided into three classes i.e. small, medium and long sentences

\begin{tabular}{llllllr}
\hline Dataset & Train & \multicolumn{2}{l}{ Test } & & Total \\
\cline { 2 - 5 } & & Small $(\leq 10)$ & Medium (11-25) & Long $(>25)$ & All test & \\
\hline \#Sentences & 6881 & 229 & 526 & 218 & 973 & 7854 \\
\#Tokens & 130,105 & 1919 & 9136 & 7415 & 18,470 & 148,575 \\
\hline
\end{tabular}

Table 18 Parsing results after training two parsers on the CLE-UTB

\begin{tabular}{|c|c|c|c|c|c|c|c|}
\hline \multirow[t]{2}{*}{ CLE-UTB Version } & \multicolumn{3}{|l|}{ Gold POS } & \multicolumn{4}{|c|}{ Predicted POS } \\
\hline & $\begin{array}{l}\text { Labeled } \\
\text { recall }(\%)\end{array}$ & $\begin{array}{l}\text { Labeled } \\
\text { precision } \\
(\%)\end{array}$ & $\begin{array}{l}\text { Labeled } \\
\text { f-score }(\%)\end{array}$ & $\begin{array}{l}\text { Labeled } \\
\text { recall }(\%)\end{array}$ & $\begin{array}{l}\text { Labeled } \\
\text { precision } \\
(\%)\end{array}$ & $\begin{array}{l}\text { Labeled } \\
\text { f-score } \\
(\%)\end{array}$ & $\begin{array}{l}\text { POS } \\
\text { accuracy } \\
(\%)\end{array}$ \\
\hline Stanford Parser & 79.0 & 77.9 & 78.4 & 75.1 & 74.3 & 74.7 & 94.9 \\
\hline BiLSTM Parser & 87.1 & 89.2 & 88.1 & 85.7 & 86.7 & 86.2 & 96.3 \\
\hline
\end{tabular}

Publisher's Note Springer Nature remains neutral with regard to jurisdictional claims in published maps and institutional affiliations. 